\title{
Oral Bacteria Are Responsible for the Etiology of Rheumatoid Arthritis
}

\author{
Mesut Ogrendik \\ Division of Physical Therapy and Rheumatology, Selcuk State Hospital, Selcuk, Turkey \\ Email: yaseminogrendik@superonline.com
}

Received 29 May 2014; revised 29 June 2014; accepted 29 July 2014

Copyright (C) 2014 by author and Scientific Research Publishing Inc.

This work is licensed under the Creative Commons Attribution International License (CC BY). http://creativecommons.org/licenses/by/4.0/

c) (i) Open Access

\begin{abstract}
A significant association has been shown to exist between periodontitis and rheumatoid arthritis (RA) in observational studies. Some intervention studies have suggested that periodontal treatment can reduce serum inflammatory biomarkers such as C-reactive protein, or erythrocyte sedimentation rate. Serum antibodies to oral bacteria have been found at increased levels in RA patients. In addition, DNAs from these bacteria have been identified from samples of RA patients. Several antibiotics are effective on RA. Finally, oral bacteria are responsible for the etiology of RA.
\end{abstract}

\section{Keywords}

\section{Rheumatoid Arthritis, Etiology, Oral Bacteria}

\section{Introduction}

Rheumatoid arthritis (RA) is a systemic, inflammatory, and autoimmune disorder and is characterized by persistent synovitis, systemic inflammation, and autoantibodies (particularly to rheumatoid factor and citrullinated peptide) [1] [2].

The diseases collectively termed periodontitis are bacterial infections which begin with inflammation of the periodontium, and can progress to loss of teeth [3]. Untreated infections lead to destruction of the periodontal ligement and alveolar bone [3]. It is estimated that over 49,000,000 people in the United States have some form of periodontitis [3]. These diseases are infectious conditions which may progress over several years with episodes of exacerbation and remission [3].

Several cross-sectional studies found that PD prevalence was higher in patients with RA than in those without [4]-[6]. The prevalence of RA was higher in PD patients compared to individuals without PD [7]. Two observational studies found an association between PD and RA severity [8] [9], and several studies found RA severity reduction by controlling PD [10]-[12]. 


\section{Periodontopathic Bacteria}

Porphyromonas gingivalis belongs to the phylum Bacteroidetes and is a non-motile, Gram-negative, rod-shaped, anaerobic pathogenic bacterium [13]. It forms black colonies on blood agar. P. gingivalis is divided into K-serotypes based upon capsular antigenicity of the various types. Arg-Gingipain (Rgp) and Lys-Gingipain (Kgp) are the gingipains secreted by $P$. gingivalis [13]. The gingipains serve many functions for the organism, which contributes to its survival and virulence [13]. Arg-gingipains have been found to play a key role in the collection of nutrients for $P$. gingivalis survival [13]. P. gingivalis fimbriae were found to be associated with modulating $\beta 2$ integrin adhesive activity for uptake by monocytes using the CD14/TLR2/PI3K signaling complex, which may contribute to intracellular evasion tactics, by P. gingivalis [14]. Calprotectin is a cytosolic protein with antibacterial action in leukocytes and its level increases in some inflammatory diseases, including PD, RA and ulcerative colitis [15]. It was found that the lipopolysaccharide of $P$. gingivalis (P-LPS) induced calprotectin release from human neutrophils. P-LPS, a major virulence factor of periodontal pathogens, is known to induce the production and release of inflammatory cytokines through CD14, Toll-like receptor (TLR) and nuclear factor kappaB (NF-kappaB). Calprotectin release is induced by P-LPS via the CD14-TLR2-NF-kappaB signal pathway in human neutrophils [15].

Tannerella forsythia is an anaerobic, Gram-negative species of bacteria of the Cytophaga-Bacteroidetes family implicated in PD. T. forsythia is a member of the red complex of periodontal pathogens [13].

Treponema denticola is a Gram-negative, obligate anaerobic, motile and highly proteolytic bacterium [13]. This Gram-negative oral spirochete is associated with the incidence and severity of human PD. T. denticola levels in the mouth are elevated in patients with PDs and the species is considered one of the main etiological agents of periodontitis [13].

These bacteria contain peptidylarginine deiminases (PADs), which are associated with the incidence and severity of human PD. Their levels in the mouth are elevated in patients with PD [13].

\section{Citrullination}

Citrullination, the process in which citrulline-containing proteins are formed, seems to have a role in several autoimmune diseases [16]. Although citrulline is a common metabolite present throughout the human body, it is a non-standard amino acid, which means that it cannot be incorporated into proteins during protein synthesis. Citrulline-containing proteins can only be generated through post-translational modification of arginine residues, a reaction that is catalysed by PAD enzymes [16].

Fibrin and fibrinogen may be favored sites for arginine deimination within rheumatoid joints. Test for presence of anti-citrullinated protein (ACP) antibodies are highly specific (88\% - 96\%) for RA, about as sensitive as rheumatoid factor $(70 \%-78 \%)$ for diagnosis of RA, and are detectable from even before the onset of clinical disease [17].

Citrullinated vimentin may be an autoantigen in RA and other autoimmune diseases, and is used to study RA. Moreover, antibodies against mutated citrullinated vimentin (MCV) may be useful for monitoring effects of RA therapy [18].

In 2001, Ogrendik et al. first hypothesized that in a genetically susceptible (shared epitope-positive) individual, immune tolerance to endogenous citrullinated antigens may be broken with subsequent development of anticyclic citrullinated peptide antibodies, which are associated with the development of RA [19] [20]. The ubiquitous enzyme enolase is a candidate antigen because a citrullinated form of enolase has been identified as an autoantigen in RA [21]. The incubation of wild type $P$. gingivalis with fibrinogen or $\alpha$-enolase destroys these proteins and the citrullination of the carboxyl-terminal arginine residues [22] $P$. gingivalis titration in RA patients is correlated with the concentration of anticitrullinated protein/peptide antibodies [23].

Finally, $P$. gingivalis, T. forsythensis, and T. denticola contain the enzyme PAD, which is involved in citrullination.

\section{Etiology of Rheumatoid Artritis}

Ogrendik et al. observed higher serum levels of antibodies against disease-causing periodontal bacteria in RA patients compared to a control group in a case-control study and reported that anti- $P$. gingivalis antibodies were more frequently observed in RA patients than healthy controls [20]. Furthermore, the concentrations of autoan- 
tibodies that are related to RA and C-reactive protein are also higher in people with P. gingivalis infections. This study was conducted from August 2001 to August 2002 in Turkey and Australia. Similar results have been demonstrated in other case-control studies [24]-[26].

However, the detection of bacterial DNA, rather than antibodies, in the synovial fluid of RA patients is a more significant result because it indicates the transfer of bacterial DNA from the infection site into the joints. Recent studies have focused on the determination of bacterial DNA in the joints of RA patients, using checkerboard DNA-DNA hybridization or polymerase chain reaction (PCR) detections [27] [28]. P. gingivalis, T. forsythia, and $P$. intermedia bacteria have been determined in synovial fluid samples from patients with RA and psoriatic arthritis through the detection of checkerboard DNA-DNA hybridization [27]. A recent cross-sectional study of 19 patients with periodontitis and resistant RA who received intensive therapy with disease-modifying antirheumatic drugs (e.g., methotrexate, sulfasalazine, leflunomide, and chloroquine) demonstrated the presence of P. intermedia (89.4\%), P. gingivalis (57.8\%), and Prevotella nigrescens (21.0\%) using PCR [28]. These two studies clearly support the presence of the chromosomal DNA of PD-associated bacteria in the sera and synovial fluid of RA patients. Synovial inflammation in RA facilitates the detection of oral bacterial DNA [27].

PD patients frequently experience bacteraemic episodes [29]. The frequency of bacteraemia is $13 \%$ after ultrasonic measurements; $20 \%$ after periodontal interventions; and 3\% after tooth brushing [29]. Periodontal pathogens can directly access the blood circulation [27] [28] and periodontal bacterial DNA is transported from the periodontal regions to the synovium in the form of free DNA [28].

\section{Animal Models}

The association between $P$. gingivalis and RA has been investigated in animal models. The injection of heatkilled $P$. gingivalis into the backs of rats with RA stimulates arthritic development as measured by paw swelling [30]. A P. gingivalis-induced extrasynovial, chronic inflammatory lesion noticeably stimulated the development of arthritis in this model. This same group examined preexisting PD and its effects on arthritis using a RA rat model [31]. PD was precipitated using an oral gavage with $P$. gingivalis, and arthritis was initiated using the collagen antibody-induced arthritis model. The PD rats exhibited higher inflammation levels and more radiographic joint damage following arthritis compared to rats without PD. This study demonstrated that $P$. gingivalis-induced preexisting PD enhanced the formation and severity of arthritis. These results demonstrate that PD caused by bacterial infection increases inflammation in distant synovial tissues.

In yet another investigation, DR4 transgenic rats were immunized with enolase that was isolated from P. gingivalis to specify the relationship between RA characterized by anti-citrullinated enolase peptide (anti-CEP) antibody positivity and $P$. gingivalis [32]. The anti-CEP antibody is specific to RA [33], and it is largely associated with alleles that contain the HLA-DRB1 shared epitope [33]. This study demonstrated a more severe arthritis in the rats immunized with enolase (native and citrullinated forms) isolated from both humans and bacteria compared to the control group. Furthermore, immunization with $P$. gingivalis enolase generated autoimmunity to human alpha-enolase and promoted the progression of arthritis. These results suggest that enolase from $P$. gingivalis in its most native form precipitates the onset of RA in some patients.

In a recent study, Maretz et al. [34] showed that infection with viable periodontal pathogen P.gingivalis strain W83 exacerbated collagen-induced arthritis (CIA) in a mouse model, as manifested by earlier onset, accelerated progression and enhanced severity of the disease, including significantly increased bone and cartilage destruction. The ability of $P$. gingivalis to augment CIA was dependent on the expression of a unique $P$. gingivalis peptidylarginine deiminase (PPAD), which converts arginine residues in proteins to citrulline. Infection with wild type $P$. gingivalis was responsible for significantly increased levels of autoantibodies to collagen type II and citrullinated epitopes as a PPAD-null mutant did not elicit similar host response. High level of citrullinated proteins was also detected at the site of infection with wild-type $P$. gingivalis. Together, these results suggest bacterial PAD as the mechanistic link between P. gingivalis periodontal infection and rheumatoid arthritis.

\section{Treatment of Rheumatoid Arthritis with Antibiotics}

\subsection{Sulfasalazine}

Professors Svartz, Willsteadt, and Askelof first produced sulfasalazine (SASP) as a combination of sulphapyridine and 5-aminosalicylic acid in Sweden in the 1930s [35]. During that time, the sulphonamides were the only 
valid antibiotics for the treatment of "rheumatoid polyarthritis" (RA). Svartz and her colleagues published their work on the effects of SASP for the treatment of RA in 1948 [35]. However, due to the discovery of corticosteroids in 1949 and the increased interest in gold and penicillamine, SASPs did not become the preferred RA treatment until the 1980s. In a study published in 1980, McConkey et al. restored the use of SASPs for the treatment of RA [36].

After intake, SASP is converted into sulphapyridine (SP) and 5-aminosalicylic acid (5-ASA) by the intestinal bacteria in the colon. Thirty percent of SP and the intact SASP molecule are absorbed, but 5-ASA is not [37], indicating that SP and SASP are the effective compounds for the treatment of RA [38]. The benefits of sulfamethoxazole for the treatment of RA further support the hypothesis that SP is the active reagent in SASP [39]. Finally, SASP is a type of antibiotic that can be effectively used for the treatment of RA.

In the 1940s, sulphonamides, which are effective in treating various gram-negative and -positive bacteria, were used for the treatment of periodontal diseases [40].

Two meta-analyses of a number of controlled studies indicated that SASP significantly improved the treatment of RA, in comparison with placebo [41] [42].

\subsection{Tetracyclines}

Tetracyclines are bacteriostatic antibiotics that are considered broad-spectrum antibiotics because they are active against a wide range of aerobic and anaerobic Gram-positive and Gram-negative bacteria, and against other microorganisms, including Rickettsia, Chlamydia and Plasmodium spp., and Mycoplasma pneumonia [43]. The mechanism of action behind the antibiotic properties of tetracyclines is mainly related to their ability to bind to the bacterial 30S ribosomal subunit and inhibit protein synthesis [43]. Several studies led to clinical trials with different tetracyclines, including minocycline. Initially, two double-blind, placebo-controlled trials were conducted: one by Kloppenburg et al. [44] and the minocycline in rheumatoid arthritis trial [45]. A few years later, Langevitz et al. [46] summarized the results of two previous open trials and three double-blind controlled studies. They concluded that minocycline might be beneficial in patients with rheumatoid arthritis, especially when administered early in the course of the disease or in patients with only mild disease, showing beneficial effects with respect to joint swelling and/or tenderness, laboratory parameters and patient assessments. A meta-analysis from 2003 that summarized the results from the clinical trials conducted until 2002 confirmed these beneficial effects [47].

\subsection{Macrolide Antibiotics}

The macrolides are a group of antibiotics whose activity stems from the presence of a macrolide ring, a large macrocyclic lactone ring to which one or more deoxy sugars, usually cladinose and desosamine, may be attached. The lactone rings are usually 14-, 15-, or 16-membered. Macrolides belong to the polyketide class of natural products.

Macrolides are protein synthesis inhibitors. The mechanism of action of macrolides is the inhibition of biosynthesis bacterial protein, and they are thought to do this by preventing peptidyl transferase from adding the peptidyl attached to tRNA to the next amino acid as well as by inhibiting ribosomal translocation [48].

The first trial with clarithromycin, a macrolide antibiotic, for the treatment of RA was conducted as an openlabel study in Italy [49]. This study of 18 RA patients was carried out for 6 months, and clarithromycin was found to be beneficial for RA treatment.

In a recent study, Saviola et al compared the efficacy of the addition of clarithromycin to methotrexate and methylprednisolone in active RA. This study showed that the addition of a 4-week clarithromycin cycle was efficacious in inducing the remission of the disease [50].

In 2006, Ogrendik reported a study of the use of clarithromycin for the treatment of RA [51]. This was a 6month, randomized, double blind, and placebo-controlled study. A total of 81 patients with early RA were treated with either once-daily oral clarithromycin $(500 \mathrm{mg})$ or daily oral placebo. The primary efficacy variable was the percentage of patients who had a 20\% improvement according to the American College of Rheumatology (ACR) criteria (i.e., an ACR 20 response) at 6 months. The secondary outcome measures were $50 \%$ improvement and 70\% improvement, according to ACR criteria (an ACR 50 response and an ACR 70 response, respectively). A significantly greater percentage of patients treated with $500 \mathrm{mg}$ clarithromycin met the ACR 20 response at 6 months compared with patients who received placebo (59\% vs. 33\%) (P $<0.001)$. A larger per- 
centage of patients treated with $500 \mathrm{mg}$ clarithromycin also achieved ACR 50 responses (34\% vs. 10\%) (P < $0.001)$ and ACR 70 responses $(20 \%$ vs. $3 \%)(P=0.003)$ compared with patients who received placebo, respectively. The clarithromycin was well tolerated. There were no dose-limiting toxic effects.

In 2009, Ogrendik reported on the use of another macrolide, roxithromycin, for the treatment of early RA. This was a double-blind trial [52] Adult patients with early RA who had not previously received DMARDs were enrolled and randomized to receive either once-daily oral roxithromycin (300 mg) or once-daily oral placebo for 3 months. The primary efficacy variable was the percentage of patients who had a $20 \%$ improvement according to ACR criteria at 3 months. The secondary outcome measures were 50\% improvement and 70\% improvement according to ACR criteria. The 28-joint disease activity score (DAS28) was also calculated. The roxithromycin group had 16 patients, and the placebo group had 15 patients. A significantly greater percentage of patients treated with roxithromycin experienced an ACR 20 response at 3 months compared with those who received placebo $(75 \%[n=12]$ vs. $20 \%[n=3])(P=0.002)$. Greater percentages of patients treated with roxithromycin also achieved ACR 50 responses $(56 \%[n=9]$ vs. $7 \%[n=1])(P=0.003)$ and ACR 70 responses $(44 \%[n=7]$ vs. $0 \%)(\mathrm{P}=0.004)$ compared with patients who received placebo. At month 3 , the DAS28 response rates were significantly greater with once-daily roxithromycin than with once-daily placebo $(\mathrm{P}<0.001)$. Adverse events were reported for eleven patients (69\%) in the roxithromycin group and for seven patients (47\%) in the placebo group. The most common ( $>5 \%$ ) adverse events were nausea, abdominal pain, headache, and dry mouth. There were no dose-limiting toxic effects. One participant in the roxithromycin group withdrew from the study because of severe emesis, while two withdrew from the placebo group because of a lack of efficacy.

In yet another study, Ogrendik and Karagoz used roxithromycin in patients who were known to be resistant to at least one DMARD [53]. This was a 6-month, randomized, double blind, and placebo-controlled trial. The researchers treated 100 active RA patients with either once-daily oral roxithromycin (300 mg) or daily oral placebo for 6 months. The primary efficacy variable was the percentage of patients who had a 20\% improvement according to ACR criteria at 6 months. The secondary outcome measures were $50 \%$ improvement and $70 \%$ improvement according to ACR criteria. A significantly greater percentage of patients treated with roxithromycin met the ACR $20 \%$ improvement criteria at 6 months compared with patients who received placebo (60\% vs 34\%) $(\mathrm{P}=0.009)$. Greater percentages of patients treated with roxithromycin also achieved ACR 50 responses (38\% vs $12 \%)(\mathrm{P}=0.003)$ and ACR 70 responses $(18 \%$ vs. $2 \%)(\mathrm{P}=0.008)$ compared with patients who received placebo. Roxithromycin was well tolerated, with an overall safety profile similar to that of the placebo.

Macrolide antibiotics are used to treat infections caused by gram-negative anaerobic bacteria [52]-[53]. In addition, they possess anti-inflammatory effects [49].

\section{Conclusion}

The above findings indicate that periodontopathic bacteria are responsible for the etiology of RA in a genetically susceptible host. These results will guide more comprehensive and efficacious treatment strategies for RA. Periodontal pathogens have direct systemic access to the blood circulation. Therefore, treatment with antibiotics in patients with RA is effective.

\section{Conflict of Interest Statement}

I declare that I have no conflicts of interest.

\section{References}

[1] Klareskog, L., Catrina, A.I. and Paget, S. (2009) Rheumatoid Arthritis. Lancet, 373, 659-672. http://dx.doi.org/10.1016/S0140-6736(09)60008-8

[2] Scott, D.L., Wolfe, F. and Huizinga, T.W. (2010) Rheumatoid Arthritis. Lancet, 376, 1094-1108. http://dx.doi.org/10.1016/S0140-6736(10)60826-4

[3] Cutler, C.W., Kalmar, J.R. and Genco, C.A. (1995) Pathogenic Strategies of the Oral Anaerobe, Porphyromonas gingivalis. Trends Microbiol, 3, 45-51. http://dx.doi.org/10.1016/S0966-842X(00)88874-5

[4] de Pablo, P., Dietrich, T. and McAlindon, T.E. (2008) Association of Periodontal Disease and Tooth Loss with Rheumatoid Arthritis in the US Population. The Journal of Rheumatology, 35, 70-76.

[5] Pischon, N., Pischon, T., Kröger, J., Gülmez, E., Kleber, B.M., Bernimoulin, J.P., et al. (2008) Association among 
Rheumatoid Arthritis, Oral Hygiene, and Periodontitis. Journal of Periodontology, 79, 979-986. http://dx.doi.org/10.1902/jop.2008.070501

[6] Dissick, A., Redman, R.S., Jones, M., Rangan, B.V., Reimold, A., Griffiths, G.R., et al. (2010) Association of Periodontitis with Rheumatoid Arthritis: A Pilot Study. Journal of Periodontology, 81, 223-230. http://dx.doi.org/10.1902/jop.2009.090309

[7] Ogrendik, M. (2009) Rheumatoid Arthritis Is Linked to Oral Bacteria: Etiological Association. Modern Rheumatology, 19, 453-456. http://dx.doi.org/10.3109/s10165-009-0194-9

[8] Marotte, H., Farge, P., Gaudin, P., Alexandre, C., Mougin, B. and Miossec, P. (2006) The Association between Periodontal Disease and Joint Destruction in Rheumatoid Arthritis Extends the Link between the HLA-DR Shared Epitope and Severity of Bone Destruction. Annals of the Rheumatic Diseases, 65, 905-909. http://dx.doi.org/10.1136/ard.2005.036913

[9] De Smit, M., Westra, J., Vissink, A., Van der Meer, B.D., Brouwer, E. and van Winkelhoff, A.J. (2012) Periodontitis in Established Rheumatoid Arthritis Patients: A Cross-Sectional Clinical, Microbiological and Serological Study. Arthritis Research \& Therapy, 14, R222. http://dx.doi.org/10.1186/ar4061

[10] Al-Katma, M.K., Bissada, N.F., Bordeaux, J.M., Sue, J. and Askari, A.D. (2007) Control of Periodontal İnfection Reduces the Severity of Active Rheumatoid Arthritis. Journal of Clinical Rheumatology, 13, 134-137. http://dx.doi.org/10.1097/RHU.0b013e3180690616

[11] Ribeiro, J., Leao, A. and Novaes, A.B. (2005) Periodontal Infection as a Possibleseverity Factor for Rheumatoid Arthritis. Journal of Clinical Periodontology, 32, 412-416. http://dx.doi.org/10.1111/j.1600-051X.2005.00689.x

[12] Ortiz, P., Bissada, N.F., Palomo, L., Han, Y.W., Al-Zahrani, M.S., Panneerselvam, A. and Askari, A. (2009) Periodontal Therapy Reduces the Severity of Active Rheumatoid Arthritis in Patients Treated with or without Tumor Necrosis Factor Inhibitors. Journal of Periodontology, 80, 535-540. http://dx.doi.org/10.1902/jop.2009.080447

[13] Marsh, P.D. and Martin, M.V. (2001) Oral Microbiology. 4th Edition, MPG Books Ltd., Bodmin.

[14] Hajishengallis, G., Wang, M., Harokopakis, E., Triantafilou, M. and Triantafilou, K. (2006) Porphyromonas gingivalis Fimbriae Proactively Modulate Beta2 Integrin Adhesive Activity and Promote Binding to and Internalization by Macrophages. Infection and Immunity, 74, 5658-5666. http://dx.doi.org/10.1128/IAI.00784-06

[15] Kido, J., Kido, R., Suryono, Kataoka, M., Fagerhol, M.K. and Nagata, T. (2003) Calprotectin Release from Human Neutrophils Is Induced by Porphyromonas gingivalis Lipopolysaccharide via the CD-14-Toll-Like Receptor-Nuclear Factor KappaB Pathway. Journal of Periodontal Research, 38, 557-563.

[16] Vossenaar, E.R. and Robinson, W.H. (2005) Citrullination and Autoimmune Disease: 8th Bertine Koperberg Meeting. Annals of the Rheumatic Diseases, 64, 1513-1515. http://dx.doi.org/10.1136/ard.2005.045716

[17] Coenen, D., Verschueren, P., Westhovens, R. and Bossuyt, X. (2007) Technical and Diagnostic Performance of 6 Assays for the Measurement of Citrullinated Protein/Peptide Antibodies in the Diagnosis of Rheumatoid Arthritis. Clinical Chemistry, 53, 498-504. http://dx.doi.org/10.1373/clinchem.2006.078063

[18] Nicaise Roland, P., Grootenboer Mignot, S., Bruns, A., Hurtado, M., Palazzo, E., Hayem, G., et al. (2008) Antibodies to Mutated Citrullinated Vimentin for Diagnosing Rheumatoid Arthritis in Anti-CCP-Negative Patients and for Monitoring Infliximab Therapy. Arthritis Research \& Therapy, 10, R142. http://dx.doi.org/10.1186/ar2570

[19] Ogrendik, M., Kokino, S., Ozdemir, F., Bird, P.S. and Hamlet, S. (2005) Serum Antibodies to Oral Anaerobic Bacteria in Patients with Rheumatoid Arthritis. Medscape General Medicine, 7, 2.

[20] Chen, H.H., Chen, D.Y., Lai, K.L., Chen, Y.M., Chou, Y.J., Chou, P., et al. (2013) Periodontitis and Etanercept Discontinuation Risk in Anti-Tumor Necrosis Factor-Naive Rheumatoid Arthritis Patients: A Nationwide PopulationBased Cohort Study. Journal of Clinical Rheumatology, 19, 432-438. http://dx.doi.org/10.1097/RHU.0000000000000041

[21] Kinloch, A., Tatzer, V., Wait, R., Peston, D., Lundberg, K., Donatien, P., et al. (2005) Identification of Citrullinated Alpha-Enolase as a Candidate Autoantigen in Rheumatoid Arthritis. Arthritis Research \& Therapy, 7, R1421-1429. http://dx.doi.org/10.1186/ar1845

[22] Wegner, N., Wait, R., Sroka, A., Eick, S., Nguyen, K.A., Lundberg, K., et al. (2010) Peptidylarginine Deiminase from Porphyromonas gingivalis Citrullinates Human Fibrinogen and $\alpha$-Enolase: Implications for Autoimmunity in Rheumatoid Arthritis. Arthritis Rheumatology, 62, 2662-2672. http://dx.doi.org/10.1002/art.27552

[23] Hitchon, C.A., Chandad, F., Ferucci, E.D., Willemze, A., Ioan-Facsinay, A., van der Woude, D., et al. (2010) Antibodies to Porphyromonas gingivalis Are Associated with Anticitrullinated Protein Antibodies in Patients with Rheumatoid Arthritis and Their Relatives. Journal of Rheumatology, 37, 1105-1112. http://dx.doi.org/10.3899/jrheum.091323

[24] Okada, M., Kobayashi, T., Ito, S., Yokoyama, T., Komatsu, Y., Abe, A., et al. (2011) Antibody Responses to Periodontopathic Bacteria in Relation to Rheumatoid Arthritis in Japanese Adults. Journal of Periodontology, 82, 
1433-1441. http://dx.doi.org/10.1902/jop.2011.110020

[25] Mikuls, T.R., Thiele, G.M., Deane, K.D., Payne, J.B., O’Dell, J.R., Yu, F., et al. (2012) Porphyromonas gingivalis and Disease-Related Autoantibodies in Individuals at Increased Risk of Rheumatoid Arthritis. Arthritis Rheumatology, 64, 3522-3530. http://dx.doi.org/10.1002/art.34595

[26] Mikuls, T.R., Payne, J.B., Reinhardt, R.A., Thiele, G.M., Maziarz, E., Cannella, A.C., et al. (2009) Antibody Responses to Porphyromonas gingivalis (P. gingivalis) in Subjects with Rheumatoid Arthritis and Periodontitis. International Immunopharmacology, 9, 38-42. http://dx.doi.org/10.1016/j.intimp.2008.09.008

[27] Moen, K., Brun, J.G., Valen, M., Skartveit, L., Eribe, E.K., Olsen, I., et al. (2006) Synovial Inflammation in Active Rheumatoid Arthritis and Psoriatic Arthritis Facilitates Trapping of a Variety of Oral Bacterial DNAs. Clinical and Experimental Rheumatology, 24, 656-663.

[28] Martinez-Martinez, R.E., Abud-Mendoza, C., Patiño-Marin, N., Rizo-Rodríguez, J.C., Little, J.W. and LoyolaRodríguez, J.P. (2009) Detection of Periodontal Bacterial DNA in Serum and Synovial Fluid in Refractory Rheumatoid Arthritis Patients. Journal of Clinical Periodontology, 36, 1004-1010. http://dx.doi.org/10.1111/j.1600-051X.2009.01496.x

[29] Kinane, D.F., Riggio, M.P., Walker, K.F., MacKenzie, D. and Shearer, B. (2005) Bacteraemia Following Periodontal Procedures. Journal of Clinical Periodontology, 32, 708-713. http://dx.doi.org/10.1111/j.1600-051X.2005.00741.X

[30] Bartold, P.M., Marino, V., Cantley, M. and Haynes, D.R. (2010) Effect of Porphyromonas gingivalis-Induced Inflammation on the Development of Rheumatoid Arthritis. Journal of Clinical Periodontology, 37, 405-411. http://dx.doi.org/10.1111/j.1600-051X.2010.01552.x

[31] Cantley, M.D., Haynes, D.R., Marino, V. and Bartold, P.M. (2011) Pre-Existing Periodontitis Exacerbates Experimental Arthritis in a Mouse Model. Journal of Clinical Periodontology, 38, 532-541. http://dx.doi.org/10.1111/j.1600-051X.2011.01714.x

[32] Kinloch, A.J., Alzabin, S., Brintnell, W., Wilson, E., Barra, L., Wegner, N., et al. (2011) Immunization with Porphyromonas gingivalis Enolase Induces Autoimmunity to Mammalian $\alpha$-Enolase and Arthritis in DR4-IETransgenic Mice. Arthritis Rheumatology, 63, 3818-3823. http://dx.doi.org/10.1002/art.30639

[33] Mahdi, H., Fisher, B.A., Källberg, H., Plant, D., Malmström, V., Rönnelid, J., et al. (2009) Specific Interaction between Genotype, Smoking, and Autoimmunity to Citrullinated Alpha-Enolase in the Etiology of Rheumatoid Arthritis. Nature Genetics, 41, 1319-1324. http://dx.doi.org/10.1038/ng.480

[34] Maresz, K.J., Hellvard, A., Sroka, A., Adamowicz, K., Bielecka, E., Koziel, J., et al. (2013) Porphyromonas gingivalis Facilitates the Development and Progression of Destructive Arthritis through Its Unique Bacterial Peptidylarginine Deiminase (PAD). Public Library of Science Pathog, 9, e1003627. http://dx.doi.org/10.1371/journal.ppat.1003627

[35] Svartz, N. (1948) The Treatment of Rheumatic Polyarthritis with Acid Azo Compounds. Rheumatism, 4, 180-185.

[36] McConke, B., Amos, R.S., Durham, S., Forster, P.J., Hubball, S. and Walsh, L. (1980) Sulphasalazine in Rheumatoid Arthritis. British Medical Journal, 280, 442-444. http://dx.doi.org/10.1136/bmj.280.6212.442

[37] Hoult, J.R. (1986) Pharmacological and Biochemical Actions of Sulphasalazine. Drugs, 32, 18-26. http://dx.doi.org/10.2165/00003495-198600321-00005

[38] Pullar, T., Hunter, J.A. and Capell, H.A. (1985) Which Component of Sulphasalazine Is Active in Rheumatoid Arthritis? British Medical Journal (Clinical Research Education), 290, 1535-1538. http://dx.doi.org/10.1136/bmj.290.6481.1535

[39] Ash, G., Baker, R., Rajapakse, C. and Swinson, D.R. (1986) Study of Sulphamethoxazole in Rheumatoid Arthritis. British Journal of Rheumatology, 25, 285-287. http://dx.doi.org/10.1093/rheumatology/25.3.285

[40] Ostrander, F.D. (1948) Vitamins, Sulfonamides and Antibiotics in Periodontal Therapy. Journal of the American Dental Association, 37, 279-288.

[41] Felson, D.T., Anderson, J.J. and Meenan, R.F. (1992) Use of Short-Term Efficacy/Toxicity Tradeoffs to Select Second-Line Drugs in Rheumatoid Arthritis. A Metaanalysis of Published Clinical Trials. Arthritis Rheumatology, 35, 1117-1125. http://dx.doi.org/10.1002/art.1780351003

[42] Weinblatt, M.E., Reda, D., Henderson, W., et al. (1999) Sulfasalazine Treatment for Rheumatoid Arthritis: A Metaanalysis of 15 Randomized Trials. Journal of Rheumatology, 26, 2123-2130.

[43] Garrido-Mesa, N., Zarzuelo, A. and Gálvez, J. (2013) Minocycline: Far beyond an Antibiotic. British Journal of Pharmacology, 169, 337-352. http://dx.doi.org/10.1111/bph.12139

[44] Kloppenburg, M., Breedveld, F.C., Terwiel, J.P., Mallee, C. and Dijkmans, B.A. (1994) Minocycline in Active Rheumatoid Arthritis. A Double-Blind, Placebo-Controlled Trial. Arthritis Rheumatology, 37, 629-636. http://dx.doi.org/10.1002/art.1780370505 
[45] Tilley, B.C., Alarcón, G.S., Heyse, S.P., et al., MIRA Trial Group (1995) Minocycline in Rheumatoid Arthritis. A 48-Week, Double-Blind, Placebo-Controlled Trial. Annals of International Medicine, 122, 81-89. http://dx.doi.org/10.7326/0003-4819-122-2-199501150-00001

[46] Langevitz, P. Livneh, A., Bank, I. and Pras, M. (2000) Benefits and Risks of Minocycline in Rheumatoid Arthritis. Drug Safety, 22, 405-414. http://dx.doi.org/10.2165/00002018-200022050-00007

[47] Stone, M. Fortin, P.R., Pacheco-Tena, C. and Inman, R.D. (2003) Should Tetracycline Treatment Be Used More Extensively for Rheumatoid Arthritis? Metaanalysis Demonstrates Clinical Benefit with Reduction in Disease Activity. Journal of Rheumatology, 30, 2112-2122.

[48] Kwiatkowska, B. and Maślińska, M. (2012) Macrolide Therapy in Chronic Inflammatory Diseases. Mediators of Inflammation, 2012, Article ID: 636157. http://dx.doi.org/10.1155/2012/636157

[49] Saviola, G., Abdi Ali, L., Rossini, P., et al. (2002) Clarithromycin in Rheumatoid Arthritis Patients Not Responsive to Disease-Modifying Antirheumatic Drugs: An Open, Uncontrolled Pilot Study. Clinical and Experimental Rheumatology, 20, 373-378.

[50] Saviola, G., Abdi-Ali, L., , L., et al. (2013) Clarithromycin in Rheumatoid Arthritis: The Addition to Methotrexate and Low-Dose Methylprednisolone Induces a Significant Additive Value-A 24-Month Single-Blind Pilot Study. Rheumatology International, 33, 2833-2838. http://dx.doi.org/10.1007/s00296-013-2822-0

[51] Ogrendik, M. (2007) Effects of Clarithromycin in Patients with Active Rheumatoid Arthritis. Current Medicine Research and Opinion, 23, 515-522. http://dx.doi.org/10.1185/030079906X167642

[52] Ogrendik, M. (2009) Efficacy of Roxithromycin in Adult Patients with Rheumatoid Arthritis Who Had Not Received Disease-Modifying Antirheumatic Drugs: A 3-Month, Randomized, Double-Blind, Placebo-Controlled Trial. Clinical Therapeutics, 31, 1754-1764. http://dx.doi.org/10.1016/j.clinthera.2009.08.014

[53] Ogrendik, M. and Karagoz, N. (2011) Treatment of Rheumatoid Arthritis with Roxithromycin: A Randomized Trial. Postgraduate Medicine, 123, 220-227. http://dx.doi.org/10.3810/pgm.2011.09.2478 
Scientific Research Publishing (SCIRP) is one of the largest Open Access journal publishers. It is currently publishing more than 200 open access, online, peer-reviewed journals covering a wide range of academic disciplines. SCIRP serves the worldwide academic communities and contributes to the progress and application of science with its publication.

Other selected journals from SCIRP are listed as below. Submit your manuscript to us via either submit@scirp.org or Online Submission Portal.
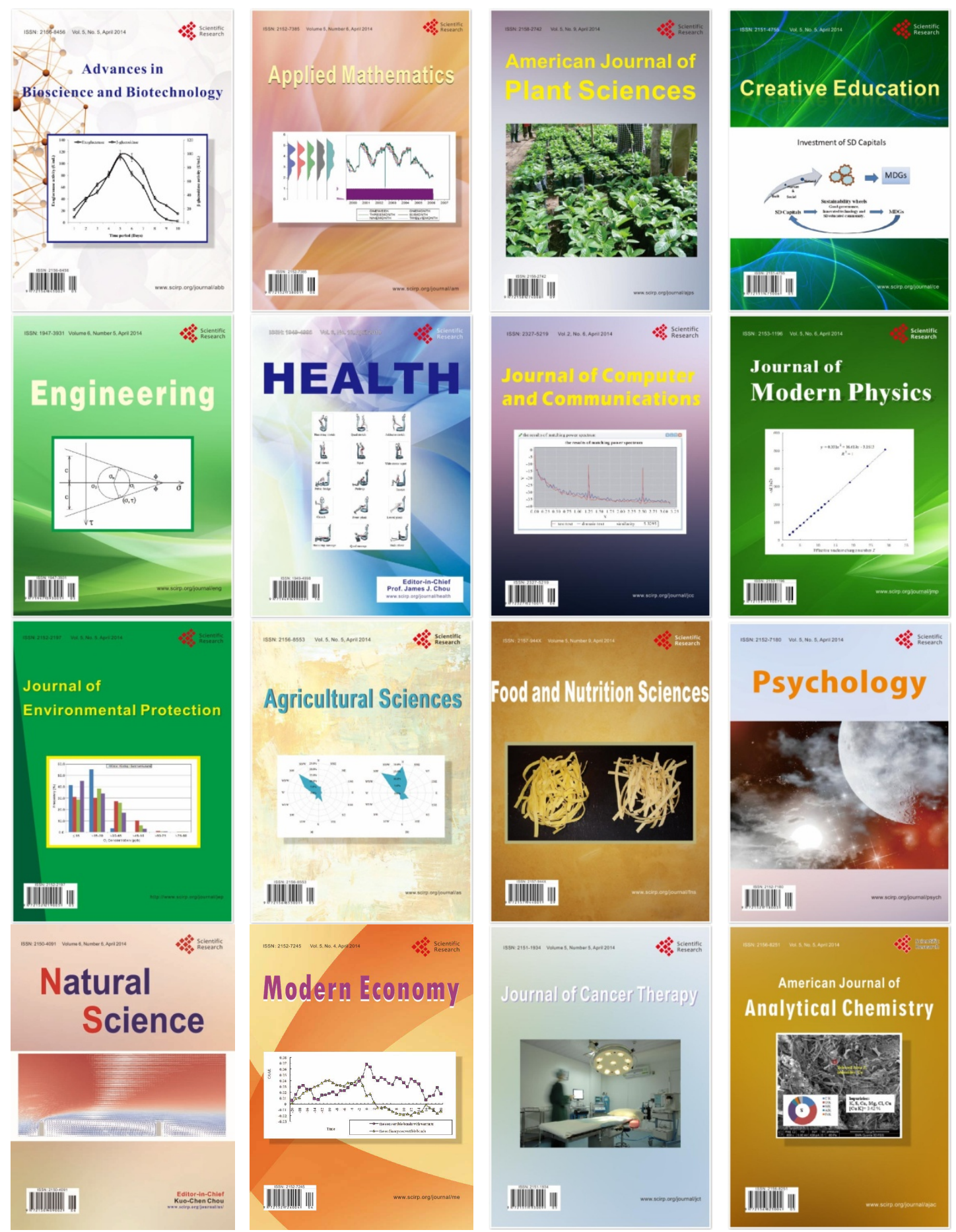